\title{
Distribution and Health Risk Assessment on Dietary Exposure of Polycyclic Aromatic Hydrocarbons in Vegetables in Nanjing, China
}

\author{
Minmin Wu, ${ }^{1,2}$ Zhonghuan Xia, ${ }^{1,2,3,4}$ Qianqian Zhang, ${ }^{1,2}$ Jing Yin, \\ Yanchi Zhou,, ${ }^{1,2}$ and Hao Yang ${ }^{2,3,4}$ \\ ${ }^{1}$ Jiangsu Provincial Key Laboratory of Materials Cycling and Pollution Control, School of Environment, Nanjing Normal University, \\ Nanjing 210023, China \\ ${ }^{2}$ Key Laboratory of Virtual Geographic Environment, Ministry of Education, Nanjing Normal University, Nanjing 210023, China \\ ${ }^{3}$ Jiangsu Center for Collaborative Innovation in Geographical Information Resource Development and Application, \\ Nanjing 210023, China \\ ${ }^{4}$ State Key Laboratory Cultivation Base of Geographical Environment Evolution in Jiangsu Province, Nanjing 210023, China
}

Correspondence should be addressed to Zhonghuan Xia; zhhxia@njnu.edu.cn

Received 18 February 2016; Revised 18 July 2016; Accepted 26 July 2016

Academic Editor: Athanasios Katsoyiannis

Copyright (C) 2016 Minmin Wu et al. This is an open access article distributed under the Creative Commons Attribution License, which permits unrestricted use, distribution, and reproduction in any medium, provided the original work is properly cited.

\begin{abstract}
In a market basket study made in Nanjing, China, in which the most common consumed nine kinds of vegetables foodstuffs were sampled, the contents of 16 polycyclic aromatic hydrocarbons (PAHs) were analyzed using gas chromatography with mass spectrometer detector (GC-MS). The results showed that the total amount of 16 PAHs was within the range of $60.5 \sim 312 \mathrm{ng} \mathrm{g}^{-1}$ (wet weight). The ranking of total concentrations for different types of vegetables in decreasing order was leafy vegetable, fruit vegetable, and rhizome vegetable. Source analysis suggested that coal, oil, or other incomplete combustion of biomass mainly contributed to the concentration of PAHs. The margin of exposure (MOE) approach with age/gender group-specific daily dietary exposure level was used to estimate the carcinogenic risk. The calculated total mean MOE in the case of BaP and PAH4 (sum of BaA, CHR, BbF, and $\mathrm{BaP}$ ) was 14960 and 7723, respectively, for local residents. In addition, the MOEs in PAH4 for some groups of both male and female were below the critical limit of 10000 proposed by EFSA. Therefore, health effect owing to the consumption of vegetables on local residents needs high concern.
\end{abstract}

\section{Introduction}

Polycyclic aromatic hydrocarbons (PAHs) are a large group of organic compounds containing two or more aromatic rings and belonging to the food and environment contaminants. They are produced by natural and anthropogenic processes.

Dietary intake of PAHs was the major source of human exposure $[1,2]$. PAHs were found as contaminants in various food categories such as vegetables, fruits, meats, cereals, oils, and milk [3]. Epidemiological studies indicate that dietary exposure to PAHs is associated with some human cancers $[4,5]$. In recent years, environmental PAH concentrations have increased in many industrialized and developing countries, leading to high levels of PAHs in foodstuffs [6]. The occurrences of PAHs in vegetables in the literatures published during the last 15 years were summarized and the subsequent dietary exposures to Benzo[a]pyrene equivalents $\left(\mathrm{BaP}_{\mathrm{eq}}\right)$ were calculated and then compared [7]. However, reports concerning cancer risk assessment of PAHs using the margin of exposure (MOE) approach [8] are quite limited.

Nanjing is a major city in southeastern China. It has more than 800 million inhabitants and is surrounded by mountains, with petrochemical, steel, and heavy industry as its economic pillars. Large amounts of pollutants have been poured into soil, water, and air owing to the combustion of fossil fuels and might seriously affected local environmental quality. Thus, obtaining the health risk level of citizens in Nanjing associated with the dietary intake of PAHs is 
essential for effective environmental management. However, such information is not available currently, leaving a great information gap. The objective of this study is to quantify the daily dietary PAH exposure level for different population groups in Nanjing and to estimate the cancer risk using MOEs.

\section{Material and Methods}

2.1. Sampling. In May 2015, nine kinds of vegetables, including Chinese cabbage, green vegetables, cauliflower, cucumber, tomato, eggplant, rhizoma dioscoreae, potato, and lotus root, which have been surveyed as the primary vegetables consumed by local residents, were purchased in representative supermarkets, wholesale markets in Nanjing, China. We collected five samples for each kind of vegetable and each sample was mixed with five subsamples. Only edible parts of each foodstuff were surveyed in this study. All collected samples were transported to laboratory as soon as possible and preserved at $-15^{\circ} \mathrm{C}$ before experimental analysis.

2.2. Analytical Procedure. The extraction and cleanup procedures of PAHs were similar to those of organochlorine pesticides in previous research [9]. Each samples of $10.0 \mathrm{~g}$ wet weight were mixed with $20 \mathrm{~mL}$ acetonitrile solvent and then were subjected to microwave extraction system (MES) (MARS2Xpress, CEM, USA). The vessels were heated in the microwave oven to $100^{\circ} \mathrm{C}$ at $10^{\circ} \mathrm{C} / \mathrm{min}$ and held for $10 \mathrm{~min}$. After extraction, the contents in the vessels were transferred to the centrifugal and were centrifuged 3 times. Then $100 \mathrm{~mL}$ $4 \%$ sodium sulfate solution was added into a separating funnel with the eluent and the mixture was extracted twice with $30 \mathrm{~mL}$-hexane. After extraction, total extracts were concentrated to $1 \mathrm{~mL}$ using a vacuum rotary evaporator and were transferred to the alumina silica gel column which were eluted with n-hexane $(20 \mathrm{~mL})$ and dichloromethane $(70 \mathrm{~mL})$ for purification before being transferred with $1 \mathrm{~mL}$ of n-hexane to a chromatography column. The samples were stored at $-4^{\circ} \mathrm{C}$ before analysis.

The concentrations of PAHs were determined by using gas chromatography-mass spectrometry (QP2010, Shimadzu, Japan) with a $30 \mathrm{~m} \times 0.25 \mathrm{~mm}$ i.d. $\times 0.25 \mu \mathrm{m}$ film thickness HP-5MS capillary column. GC temperature was programmed from an initial $60^{\circ} \mathrm{C}$ before commencing at $5^{\circ} \mathrm{C} / \mathrm{min}$ up to $280^{\circ} \mathrm{C}$, with a final holding time of $20 \mathrm{~min}$. Helium was used as the carrier gas and operated in splitless mode at a flow rate of $1 \mathrm{~mL} / \mathrm{min}$. The head column pressure was $30 \mathrm{kPa}$. The mass spectrometer was operated in scan mode with an electron impact ionization of $70 \mathrm{eV}$, an electron multiplier voltage of $1288 \mathrm{~V}$, and an ion source of $230^{\circ} \mathrm{C}$. Concentrations were determined for 16 PAHs in all samples. They were naphthalene (NAP), acenaphthene (ACE), acenaphthylene (ACY), fluorine (FLO), phenanthrene (PHE), anthracene (ANT), fluoranthene (FLA), pyrene (PYR), benz(a)anthracene $(\mathrm{BaA})$, chrysene $(\mathrm{CHR})$, benzo(b)fluoranthene $(\mathrm{BbF})$, benzo(k)fluoranthene $(\mathrm{BkF})$, benzo(a)pyrene $(\mathrm{BaP})$, dibenz $(\mathrm{a}, \mathrm{h})$ anthracene $(\mathrm{Dah} A)$, indeno(1,2,3cd)pyrene (IcdP), and benzo(g,h,i)perylene (BghiP).
2.3. Quality Control. All solvents used were chromatography purity. Alumina and silica gel (80-200 mesh; Dikma, China) were heated at $650^{\circ} \mathrm{C}$ in a muffle furnace (DLII-9, Beijing, China) for $10 \mathrm{~h}$, kept in a sealed desiccator, and reactivated at $130^{\circ} \mathrm{C}$ for $4 \mathrm{~h}$ immediately prior to use. All glassware was cleaned using an ultrasonic cleaner (KQ-500B, Kunshan, China) and heated to $400^{\circ} \mathrm{C}$ for $6 \mathrm{~h}$. Quantification was performed by the use of external calibrations which were obtained with $\mathrm{PAH}$ solutions at five concentration levels. The procedural blank was determined by going through the extraction and cleanup procedures using glass beads and all the results of food samples were laboratory procedure blank corrected. Recovery of individual PAHs ranged from $71.0 \% \pm$ $3.3 \%$ to $122 \% \pm 6.1 \%$ with a mean value of $103 \% \pm 4.5 \%$ for the 16 PAHs. Data analyzed in the paper were not corrected for recoveries. The detection limit for different food samples was in the range of $0.0018 \sim 0.014 \mathrm{ng} / \mathrm{g}$ wet weight.

2.4. Dietary Exposure Assessment. The population of Nanjing was divided into eight groups according to age and gender: children (4-10 years), adolescents (11-17 years), adults (18-60 years), and seniors (61-70 years) of male as well as the above groups of female. Daily dietary BaP or PAH4 (sum of BaA, $\mathrm{CHR}, \mathrm{BbF}$, and $\mathrm{BaP}$ ) exposure level $(E)$ for each population group was calculated as follows:

$$
E=C \times \mathrm{IR}
$$

where $E$ is daily dietary BaP or PAH4 exposure level (ng/day); $\mathrm{C}$ is $\mathrm{BaP}$ or $\mathrm{PAH} 4$ concentration in vegetables $(\mathrm{ng} / \mathrm{g})$; IR is ingestion amount of vegetables per day (g/day) [10-12].

2.5. Cancer Risk Assessment. The scientific opinion of European Food Safety Authority (EFSA) on a harmonized approach for risk assessment of substances which are both genotoxic and carcinogenic [13] was used to characterize the risk related to consumption of vegetables. In general, it was assumed that the margin of exposure (MOE) of 10000 or higher would be of low concern from the viewpoint of public health and might be considered low priority for risk management actions [14]. The $\mathrm{BMDL}_{10}$ (benchmark dose lower confidence limit 10\%), an estimate of the lowest dose which is $95 \%$ certain to cause no more than a $10 \%$ cancer incidence in rodents, was used to obtain the MOE. MOE for each population group was calculated as follows:

$$
\mathrm{MOE}=\frac{\mathrm{BMDL}_{10} \times \mathrm{BW}}{E},
$$

where $\mathrm{MOE}$ is the margin of exposure for $\mathrm{BaP}$ or $\mathrm{PAH} 4$ (dimensionless); $E$ is daily dietary $\mathrm{BaP}$ or PAH4 exposure level (ng/day); BW is body weight of each population group (kg) [10-12]; $\mathrm{BMDL}_{10}=70 \mu \mathrm{g} / \mathrm{kg}$ bw/day (for $\mathrm{BaP}$ ) or $340 \mu \mathrm{g} / \mathrm{kg}$ bw/day (for PAH4) [15].

\section{Results and Discussion}

3.1. Concentrations of PAHs in Vegetables. Vegetable samples were divided into three groups-leafy vegetable, melon 


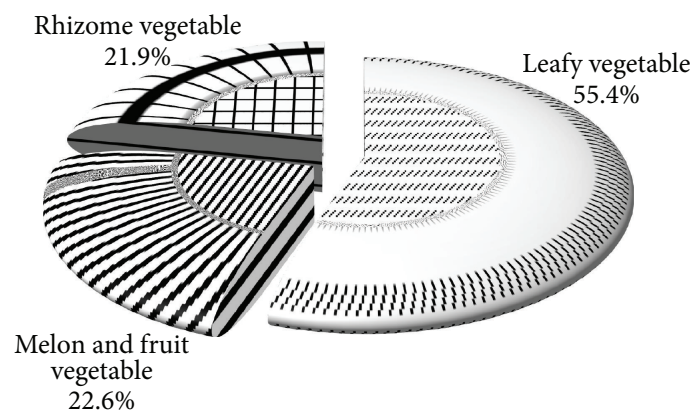

Figure 1: Percentage distribution of PAH16 in different groups of vegetables.

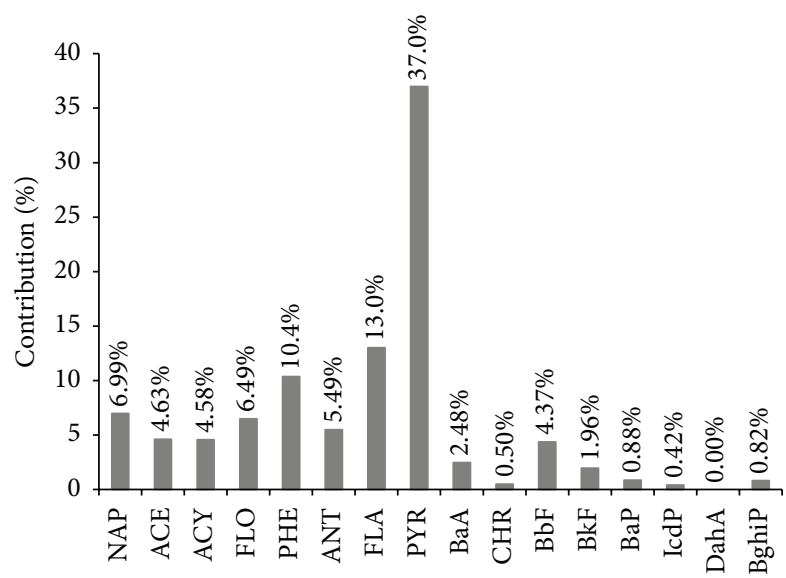

FIgURE 2: Relative contribution of individual PAH to PAH16 in the vegetables.

and fruit vegetable, and rhizome vegetable. The mean and standard deviation values of single $\mathrm{PAH}$ compound, as well as the total content of PAHs, are shown in Table 1. The concentrations of 16 PAHs ranged from 60.5 to $312 \mathrm{ng} \mathrm{g}^{-1}$ (wet weight). The observed PAH16 concentrations in this study were much lower than those in vegetables growing near an iron and steel industrial area in Nanjing in 2007 $\left(227 \sim 1533 \mathrm{ng} \mathrm{g}^{-1}\right)$ [16], but higher than $25.0 \sim 290 \mathrm{ngg}^{-1}$ in vegetables grown in an industrial Greek area [17]. According to Figure 1, the three groups of vegetable samples in PAH16 ranked in the order: leafy vegetable $>$ melon and fruit vegetable $>$ rhizome vegetable. The highest level of PAH16 was detected in Chinese cabbage $\left(312 \mathrm{ng} \mathrm{g}^{-1}\right)$ followed by cauliflower $\left(198 \mathrm{ng} \mathrm{g}^{-1}\right)$ and tomato $\left(105 \mathrm{ng} \mathrm{g}^{-1}\right)$ whereas cucumber $\left(60.5 \mathrm{ng} \mathrm{g}^{-1}\right)$ accumulated the lowest amount. Due to the difference of surface/mass ratio, the leafy vegetable such as green vegetables and Chinese cabbage, which have large surface area, showed high values of PAHs contents [14, 18]. Another study also found that the highest concentration was in the leafy vegetable, followed by melon and fruit vegetable, while the lowest concentration was found in the rhizome vegetable [16]. Relative contribution of individual $\mathrm{PAH}$ to PAH16 in vegetables is shown in Figure 2. The 16 PAHs in all kinds of vegetables ranked in the order PYR $>\mathrm{FLA}>\mathrm{PHE}>\mathrm{NAP}>\mathrm{FLO}>\mathrm{ANT}>\mathrm{BbF}>\mathrm{ACY}>$ $\mathrm{ACE}>\mathrm{BaA}>\mathrm{BkF}>\mathrm{BaP}>\mathrm{CHR}>\mathrm{BghiP}>\mathrm{IcdP}>\mathrm{DahA}$.

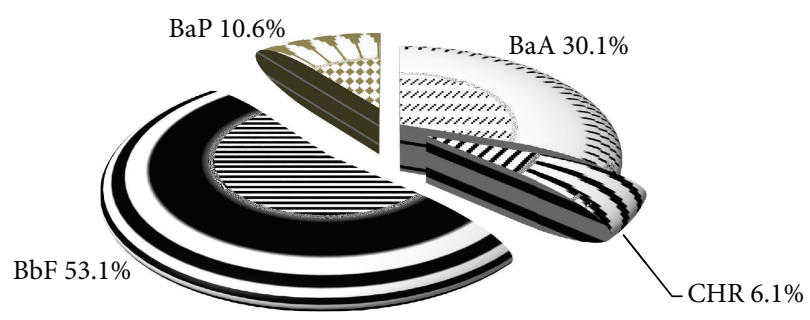

FIgURE 3: General distribution of PAH4 analytes (\%).

Low-molecular-weight compounds, such as NAP, FLO, ANT, PHE, FLA, and PYR, took the dominant place in PAHswhile higher-molecular-weight PAHs showed relatively low levels.

The highest level of PAH4 for individual samples was found in green vegetables $\left(19.6 \mathrm{ng} \mathrm{g}^{-1}\right.$ ) (Table 1), owing to the high concentration of $\mathrm{BbF}$ (Figure 3). The concentrations of PAH4 in Chinese cabbage, green vegetables, and tomato exceeded the maximum level (ML) of $12 \mathrm{ngg}^{-1}$ for PAH4 (Commission Regulation (EC) number 1881/2006 amended by Commission Regulation (EU) number 835/2011) [19]. The PAH4 values observed in eggplant and cucumber were higher than those reported for Pakistan [20] and Wuhan, China [21]. The mean $\mathrm{BaP}$ content was $1.05 \mathrm{ng} \mathrm{g}^{-1}$ in vegetables, which was significantly below the ML of $5 \mathrm{ng} \mathrm{g}^{-1}$ in China (GB27622012) and was lower than ML for Bap in $2011\left(2 \mathrm{ng} \mathrm{g}^{-1}\right)$ [19]. However, concentrations of $\mathrm{BaP}$ in some kinds of samples, such as Chinese cabbage, rhizoma dioscoreae, and lotus root, exceeded $2 \mathrm{ng} \mathrm{g}^{-1}$.

3.2. Identification of PAH Sources. PAHs molecular diagnostic ratios have long been used as a tool for PAHs source identification purposes [22-29] whereas some molecular diagnostic ratios were suggested to be of limited use as a source identification tool $[30,31]$. In this study, relatively more stable ratios of $\mathrm{BaA} /(\mathrm{BaA}+\mathrm{Chr})[30]$ and $\mathrm{IcdP} /(\mathrm{IcdP}$ + BghiP) [31] were calculated to identify the sources of PAHs in the vegetables (Table 2). It was found that the above ratios were 0.83 and 0.34 , respectively, which exceeded 0.35 and ranged from 0.20 to 0.50 , respectively, indicating that sources of PAHs might be combustion and petroleum.

By importing the concentrations of samples into SPSS 20 with the method of $\mathrm{R}$ cluster analysis, it was found that the data were divided into six groups (Figure 4). The first group consisted of IcdP, BghiP, BkF, and BaP, and the second group included $\mathrm{BaA}, \mathrm{CHR}$. DahA belonged to the third group whereas NAP, BbF, and ACY were part of the fourth group. The fifth group included ANT and the sixth group consisted of ACE, PHE, FLO, PYR, and FLA. Some studies found that PHE, ANT, ACE, FLO, and PYR are considered to be the emission of coal combustion $[32,33]$ whereas BghiP and IcdP are tracers for vehicular fuels [28].

Vegetables in this study were sampled in wholesale markets and supermarkets in Nanjing city, which implied that these vegetables were from a wide variety of producing areas in several provinces in China, not only from Nanjing. With the relatively more stable ratios of $\mathrm{BaA} /(\mathrm{BaA}+\mathrm{Chr})$ and IcdP/(IcdP + BghiP) as well as the method of R cluster 


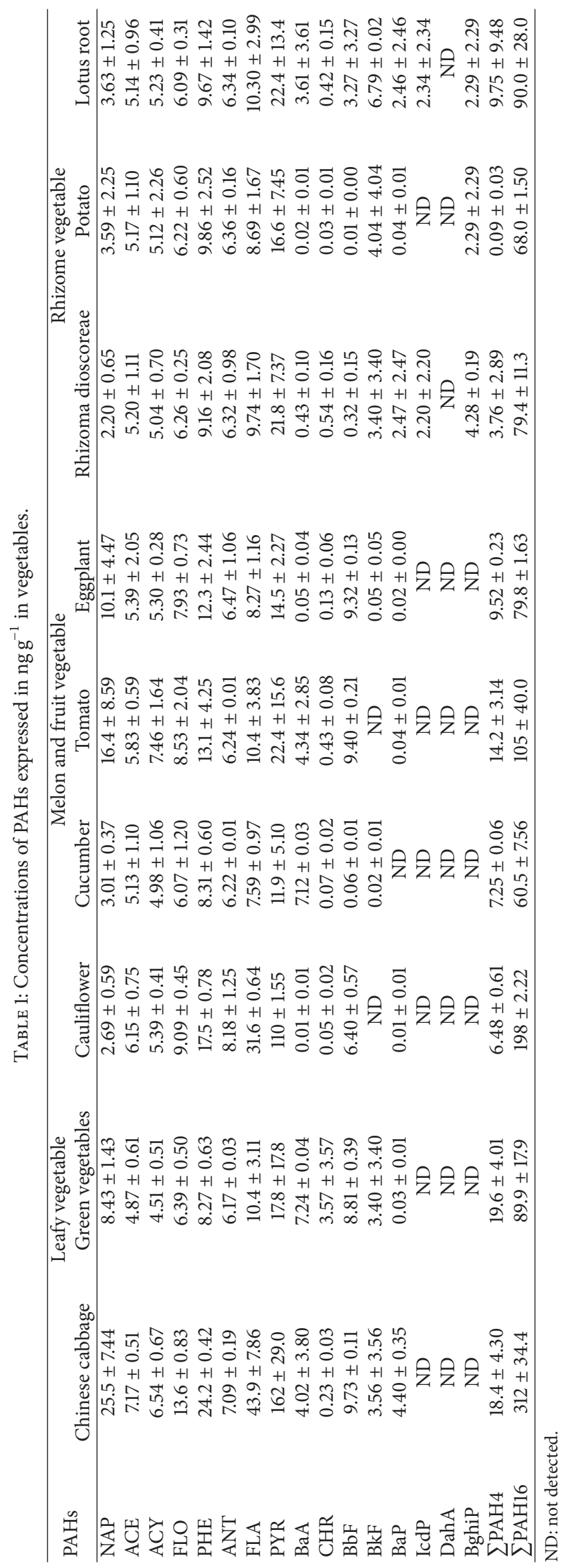


TABLE 2: PAH isomer ratios commonly used in the identification of PAH sources.

\begin{tabular}{|c|c|c|c|c|c|}
\hline \multirow[b]{2}{*}{ Ratio } & \multicolumn{5}{|c|}{ PAH source } \\
\hline & $\begin{array}{l}\text { Petroleum } \\
\text { (unburned) }\end{array}$ & $\begin{array}{l}\text { Petroleum } \\
\text { (combustion) }\end{array}$ & $\begin{array}{l}\text { Petroleum and } \\
\text { combustion } \\
\text { (mixed) }\end{array}$ & Combustion & $\begin{array}{l}\text { Biomass/coal } \\
\text { combustion }\end{array}$ \\
\hline $\mathrm{BaA} /(\mathrm{BaA}+\mathrm{Chr})$ & $<0.20$ & & $0.20-0.35$ & $>0.35$ & \\
\hline $\mathrm{IcdP} /(\mathrm{IcdP}+\mathrm{BghiP})$ & $<0.20$ & $0.20-0.50$ & & & $>0.50$ \\
\hline
\end{tabular}

TABLE 3: The mean values of daily dietary PAHs exposure for population groups in Nanjing (ng day $\left.{ }^{-1}\right)$.

\begin{tabular}{lcccccccc}
\hline & \multicolumn{2}{c}{ Male } & \multicolumn{4}{c}{ Female } \\
& Children & Adolescents & Adults & Seniors & Children & Adolescents & Adults & Seniors \\
\hline BaP & 173 & 249 & 272 & 270 & 160 & 223 & 254 & 246 \\
PAH4 sum & 1627 & 2339 & 2558 & 2541 & 1504 & 2099 & 2385 & 2315 \\
\hline
\end{tabular}

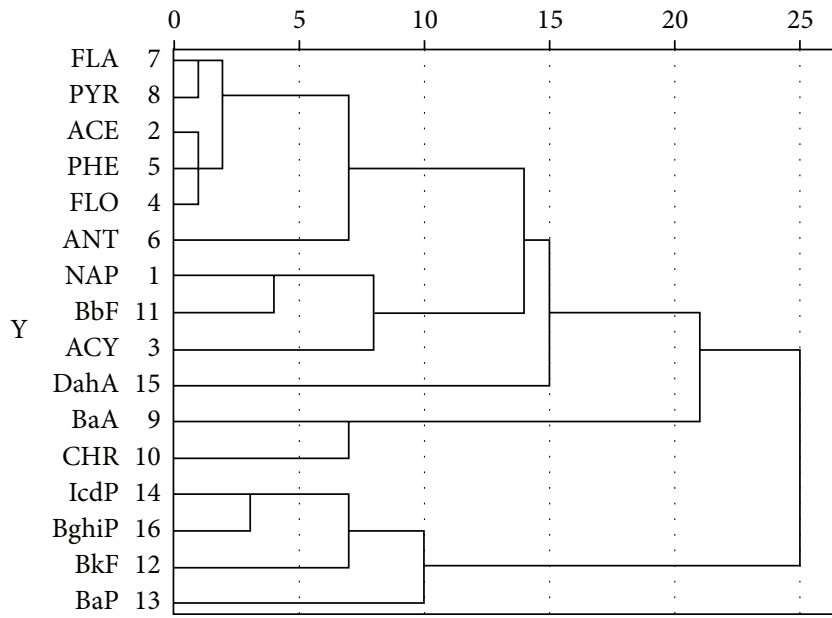

FIGURE 4: Clustering tree of PAH concentration in vegetables.

analysis, the possible pollution sources of PAHs in vegetables in the producing areas might mainly be coal combustion and petroleum.

3.3. Dietary Exposure. The dietary exposure to PAHs for each population group in Nanjing is shown in Table 3. The mean $\mathrm{BaP}$ concentrations of dietary exposure in eight groups (boys, male adolescents, male adults, male seniors, girls, female adolescents, female adults, and female seniors) were 173, $249,272,270,160,223,254$, and $246 \mathrm{ng}$ day $^{-1}$, respectively. The total dietary exposure of male $\left(963 \mathrm{ng} \mathrm{day}^{-1}\right.$ ) was more than that of female $\left(883 \mathrm{ng} \mathrm{day}^{-1}\right)$. Moreover, the ranking of population groups for dietary intake of $\mathrm{BaP}$ in decreasing order was male adults, male seniors, female adults, male adolescents, female seniors, female adolescents, boys, and girls. Daily dietary exposure to $\mathrm{B}[\mathrm{a}] \mathrm{P}_{\mathrm{eq}}$ among above eight groups in Taiyuan, China, was 392, 511, 572, 533, 355, 441, 488 , and 445 ng day $^{-1}$, respectively [3]. The dietary exposure in Nanjing was lower than that in Taiyuan. The first reason might be the more serious pollution level in Taiyuan. In addition, the dietary exposure of a variety of foods, which included vegetables, fruits, rice, wheat, fish, pork, chicken, eggs, milk, oils, beef, and mutton, was assessed in Taiyuan whereas in Nanjing only that of vegetables was estimated. A third reason was that the toxicity equivalency factors (TEFs) were used to estimate the dietary exposure in Taiyuan and the TEFs in high rings of PAHs were large, which resulted in higher values of $\mathrm{B}[\mathrm{a}] \mathrm{P}_{\text {eq }}$. Exposure dose among different population groups in Lanzhou, China, was female adult $>$ male adult $>$ girls $>$ boys [34]. This result was not the same as our study due to the fact that the exposures in Lanzhou included not only dietary exposure, but inhalation exposure and skin exposure.

The mean PAH4 concentrations of dietary exposure for the above eight groups in Nanjing were 1627, 2339, 2558, $2541,1504,2099,2385$, and $2315 \mathrm{ng} \mathrm{day}^{-1}$, respectively. The total dietary exposure of male ( $9064 \mathrm{ng} \mathrm{day}^{-1}$ ) was also more than that of female $\left(8304 \mathrm{ng} \mathrm{day}^{-1}\right)$ in this case. Moreover, the ranking order of population groups for dietary intake of PAH4 was the same as that of BaP. The total PAH16 concentration of dietary exposure in Catalonia, Spain, was different from our study: male adolescents $>$ male adults $>$ boys $>$ female adolescents $>$ girls and male seniors > female adults $>$ female seniors [35]. Part of the reason for the difference between the two studies may be well related to the fact that ingestion amounts of vegetables for population groups in Nanjing were different from that in Catalonia. Another reason might be that different kinds of PAHs were chosen to calculate the exposure.

3.4. Risk Assessment. The values of MOE indicators in case of $\mathrm{BaP}$ and $\mathrm{PAH} 4$ for all residents and different population groups in Nanjing were demonstrated in Table 4. It can be found that MOEs calculated for mean exposure using EFSA BMDL10 of $70 \mu \mathrm{g} / \mathrm{kg}$ bw/day, EFSA for BaP were more than 10000, whereas that using EFSA BMDL10 of $340 \mu \mathrm{g} / \mathrm{kg}$ bw/day, EFSA for PAH4 were far less than 10000. According to the calculation, it was found that higher dietary exposure resulted in lower MOE values. Compared with the eight groups, a relatively lower MOE is characteristic for children. It may be due to the fact that children were more sensitive and were easier to be exposed to the environmental pollutants. 
TABLE 4: MOE indicators within different population groups in Nanjing.

(a)

\begin{tabular}{|c|c|c|c|c|c|c|c|c|c|c|c|}
\hline & \multicolumn{3}{|c|}{$\begin{array}{c}\text { Consumption of } \\
\text { vegetables }\left(\mathrm{g} \mathrm{day}^{-1}\right)\end{array}$} & \multirow{2}{*}{$\begin{array}{c}\text { Mean } \\
\mathrm{BaP} / \sum \mathrm{PAH} 4 \\
(\mathrm{ng} / \mathrm{g})\end{array}$} & \multicolumn{3}{|c|}{$\begin{array}{l}\text { Population exposure } \\
\left(\text { ng kg }^{-1} \text { b.w. day }\right.\end{array}$} & \multirow{2}{*}{ 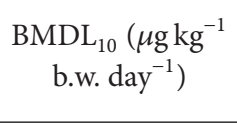 } & \multicolumn{3}{|c|}{$\mathrm{MOE}$} \\
\hline & Mean & Median & $75 \%$ tile & & Mean & Median & $75 \%$ tile & & Mean & Median & $75 \%$ tile \\
\hline $\mathrm{BaP}$ & 219 & 235 & 258 & 1.05 & 4.68 & 5.02 & 5.50 & 70 & 14960 & 13956 & 12728 \\
\hline PAH4 sum & 219 & 235 & 258 & 9.90 & 44.0 & 47.2 & 51.7 & 340 & 7723 & 7204 & 6571 \\
\hline
\end{tabular}

(b)

\begin{tabular}{|c|c|c|c|c|c|c|}
\hline \multirow{2}{*}{ Population groups } & \multicolumn{3}{|c|}{ MOE (in case of mean BaP) } & \multicolumn{3}{|c|}{ MOE (in case of mean PAH4) } \\
\hline & Mean & Median & $75 \%$ tile & Mean & Median & $75 \%$ tile \\
\hline All residents & 14960 & 13956 & 12728 & 7723 & 7204 & 6571 \\
\hline \multicolumn{7}{|l|}{ Male } \\
\hline Children & 7857 & 7330 & 6685 & 4056 & 3784 & 3451 \\
\hline Adolescents & 15351 & 14320 & 13061 & 7924 & 7392 & 6742 \\
\hline Adults & 20357 & 20357 & 20357 & 10509 & 9803 & 8941 \\
\hline Seniors & 19780 & 18452 & 16829 & 10211 & 9525 & 8688 \\
\hline \multicolumn{7}{|l|}{ Female } \\
\hline Children & 7493 & 6990 & 6375 & 3868 & 3609 & 3291 \\
\hline Adolescents & 14471 & 13499 & 12312 & 7470 & 6969 & 6356 \\
\hline Adults & 17384 & 16216 & 14790 & 8974 & 8371 & 7635 \\
\hline Seniors & 16989 & 15848 & 14454 & 8770 & 8181 & 7462 \\
\hline
\end{tabular}

The MOE values in the groups of both adults and seniors in case of $\mathrm{BaP}$ were more than the critical limit of 10000 proposed by EFSA, whereas the MOE values in most groups in case of PAH4 were less than 10000, indicating a certain cancer risk.

Rozentāle studied on smoked meat products produced in Latvia and concluded a relatively higher dietary exposure and a comparatively lower MOE [14] by comparison with that in Nanjing. Different MOEs between Nanjing and Latvia may be due to the different eating habits and customs in the two regions. Veyrand found MOEs calculated for mean exposure for PAH4 were 150,000 for children and 230,000 for adults in French total diet study [8]. The results in our study were lower than the MOEs values in France, owing to the higher pollution level in Nanjing.

\section{Conclusions}

The content of PAH16 sum in the analyzed vegetables in Nanjing, China, ranged from 60.5 to $312 \mathrm{ng} \mathrm{g}^{-1}$. The mean of $\mathrm{BaP}$ content is lower than the maximum level of European Commission Regulation. Due to the differences in growth structure of vegetables, the order of the contents of PAHs in three edible vegetables was leafy vegetable $>$ fruit vegetable $>$ rhizome vegetable. Source analysis indicated that PAHs in vegetables mainly came from petroleum or other incomplete combustion biomass. The ranking of population groups for dietary intake of PAHs in decreasing order was male adults, male seniors, female adults, male adolescents, female seniors, female adolescents, boys, and girls. The calculated MOE values in the case of PAH4 sum for most population groups were less than the critical limit of 10000 proposed by EFSA, indicating a certain cancer risk.

\section{Additional Points}

Submission Declaration. The authors declare that this work described has not been published previously and that it is not under consideration for publication elsewhere, and its publication is approved by all authors and tacitly or explicitly by the responsible authorities where the work was carried out, and also, if accepted, it will not be published elsewhere including electronically in the same form, in English or in any other language, without the written consent of the copyright holder.

\section{Competing Interests}

The authors declare that there is no conflict of interests.

\section{Acknowledgments}

This study was jointly supported by the National Natural Science Foundation of China (41001344), China Postdoctoral Science Foundation Funded Project (2013M541696), Jiangsu Planned Projects for Postdoctoral Research Funds (1301040C), Program of Natural Science Research of Jiangsu Higher Education Institutions of China (13KJB610008), Program of State Key Laboratory of Environmental Criteria and Risk Assessment, Chinese Research Academy of Environmental Sciences (SKLECRA2013OFP07), Program of Graduate Education Reform and Practice of Nanjing 
Normal University (1812000002A521), Scientific Research Foundation of the High-Level Personnel of Nanjing Normal University (2012105XGQ0102), and the Priority Academic Program Development of Jiangsu Higher Education Institutions (164320H116).

\section{References}

[1] M. M. Mumtaz, J. D. George, K. W. Gold, W. Cibulas, and C. T. Derosa, "ATSDR evaluation of health effects of chemicals. IV. Polycyclic aromatic hydrocarbons (PAHs): understanding a complex problem," Toxicology and Industrial Health, vol. 12, no. 6, pp. 742-971, 1996.

[2] D. H. Phillips, "Polycyclic aromatic hydrocarbons in the diet," Mutation Research-Genetic Toxicology and Environmental Mutagenesis, vol. 443, no. 1-2, pp. 139-147, 1999.

[3] Z. Xia, X. Duan, W. Qiu et al., "Health risk assessment on dietary exposure to polycyclic aromatic hydrocarbons (PAHs) in Taiyuan, China," Science of the Total Environment, vol. 408, no. 22, pp. 5331-5337, 2010.

[4] B. M. Lee and G. A. Shim, "Dietary exposure estimation of benzo[a]pyrene and cancer risk assessment," Journal of Toxicology and Environmental Health, Part A: Current Issues, vol. 70, no. 15-16, pp. 1391-1394, 2007.

[5] M. Stacewicz-Sapuntzakis, G. Borthakur, J. L. Burns, and P. E. Bowen, "Correlations of dietary patterns with prostate health," Molecular Nutrition and Food Research, vol. 52, no. 1, pp. 114130,2008

[6] Q. Xiao and Y.-Y. Chi, "Determination of polycyclic aromatic hydrocarbons in smoked food by dispersive liquid-liquid microextraction and gas chromatography-mass spectrometry," Modern Agricultural Science \& Technology, 2012 (Chinese).

[7] H. X. Lü, Q.-Y. Cai, K. C. Jones, Q.-Y. Zeng, and A. Katsoyiannis, "Levels of organic pollutants in vegetables and human exposure through diet: a review," Critical Reviews in Environmental Science \& Technology, vol. 44, no. 1, pp. 1-33, 2014.

[8] B. Veyrand, V. Sirot, S. Durand et al., "Human dietary exposure to polycyclic aromatic hydrocarbons: results of the second French Total Diet Study," Environment International, vol. 54, pp. 11-17, 2013.

[9] Q.-S. Yang, B.-X. Mai, J.-M. Fu, G.-Y. Sheng, and J.-X. Wang, "Spatial and temporal distribution of organochlorine pesticides (OCPs) in surface water from the Pearl River Artery Estuary," Environmental Science, vol. 25, no. 2, pp. 150-156, 2004 (Chinese).

[10] K. Y. Ge, Dietary and Nutritional Status of the Population in the 1990s, People's Medical Publishing House, 1992 (Chinese).

[11] L. Wang, Chinese National Health and Nutrition Survey Report One: Diet and Nutrient Intake Status, People's Medical Publishing House, Beijing, China, 2005 (Chinese).

[12] F. Y. Zhai and X. G. Yang, Chinese National Health and Nutrition Survey Report Two: Diet and Nutrient Intake Status, People's Medical Publishing House, Beijing, China, 2006 (Chinese).

[13] EFSA, "Opinion of the scientific committee on a request from EFSA related to a harmonised approach for risk assessment of substances which are both genotoxic and carcinogenic," EFSA Journal, vol. 3, no. 10, article 282, 2005.

[14] I. Rozentāle, I. Stumpe-Vīksna, D. Začs, I. Siksna, A. Melngaile, and V. Bartkevičs, "Assessment of dietary exposure to polycyclic aromatic hydrocarbons from smoked meat products produced in Latvia," Food Control, vol. 54, pp. 16-22, 2015.
[15] EFSA, "Scientific opinion of the panel on contaminants in the food chain on a request from the European Commission on polycyclic aromatic hydrocarbons in food," EFSA Journal, vol. 724, pp. 1-114, 2008.

[16] F. Shen and L.-Z. Zhu, "Concentration and distribution of PAHs in vegetables grown near an iron and steel industrial area," Environmental Science, vol. 28, no. 3, pp. 669-672, 2007.

[17] D. Voutsa and C. Samara, "Dietary intake of trace elements and polycyclic aromatic hydrocarbons via vegetables grown in an industrial Greek area," Science of the Total Environment, vol. 218, no. 2-3, pp. 203-216, 1998.

[18] W. Zhong and M. Wang, "Some polycyclic aromatic hydrocarbons in vegetables from Northern China," Journal of Environmental Science and Health-Part A, vol. 37, no. 2, pp. 287-296, 2002.

[19] EC, "European Commission regulation no. 835/2011 of 19 August 2011 amending regulation (EC) no. 1881/2006 as regards maximum levels for polycyclic aromatic hydrocarbons in foodstuffs," Official Journal of the European Union, vol. L215, pp. 4-8, 2011.

[20] M. W. Ashraf, S. I. H. Taqvi, A. R. Solangi, and U. A. Qureshi, "Distribution and risk assessment of polycyclic aromatic hydrocarbons in vegetables grown in Pakistan," Journal of Chemistry, vol. 2013, Article ID 873959, 5 pages, 2013.

[21] F.-F. Lei, J.-Y. Huang, X.-N. Zhang, X.-J. Liu, and X.-J. Li, “Determination of polycyclic aromatic hydrocarbons in vegetables by headspace SPME-GC," Chromatographia, vol. 74, no. 1-2, pp. 99-107, 2011.

[22] I. G. Kavouras, P. Koutrakis, M. Tsapakis et al., "Source apportionment of urban particulate aliphatic and polynuclear aromatic hydrocarbons (PAHs) using multivariate methods," Environmental Science \& Technology, vol. 35, no. 11, pp. 2288-2294, 2001.

[23] M. B. Yunker, R. W. Macdonald, R. Vingarzan, R. H. Mitchell, D. Goyette, and S. Sylvestre, "PAHs in the Fraser River basin: a critical appraisal of PAH ratios as indicators of PAH source and composition," Organic Geochemistry, vol. 33, no. 4, pp. 489-515, 2002.

[24] C. P. Kaushik, P. Sangwan, and A. K. Haritash, "Association of Polycyclic Aromatic Hydrocarbons (PAHs) with different sizes of atmospheric particulate in Hisar city and its health aspects," Polycyclic Aromatic Compounds, vol. 32, no. 5, pp. 626-642, 2012.

[25] J. Wang, N. B. Geng, Y. F. Xu, W. D. Zhang, X. Y. Tang, and R. Q. Zhang, "PAHs in $\mathrm{PM}_{2.5}$ in Zhengzhou: concentration, carcinogenic risk analysis, and source apportionment," Environmental Monitoring and Assessment, vol. 186, no. 11, pp. 7461-7473, 2014.

[26] A. A. Jamhari, M. Sahani, M. T. Latif et al., "Concentration and source identification of polycyclic aromatic hydrocarbons (PAHs) in PM10 of urban, industrial and semi-urban areas in Malaysia," Atmospheric Environment, vol. 86, pp. 16-27, 2014.

[27] N. Ré, V. M. F. Kataoka, C. A. L. Cardoso, G. B. Alcantara, and J. B. G. De Souza, "Polycyclic aromatic hydrocarbon concentrations in gas and particle phases and source determination in atmospheric samples from a semiurban area of Dourados, Brazil," Archives of Environmental Contamination and Toxicology, vol. 69, no. 1, pp. 69-80, 2015.

[28] C. Bourotte, M.-C. Forti, S. Taniguchi, M. C. Bícego, and P. A. Lotufo, "A wintertime study of PAHs in fine and coarse aerosols in São Paulo city, Brazil," Atmospheric Environment, vol. 39, no. 21, pp. 3799-3811, 2005. 
[29] P. F. Chen, S. C. Kang, C. L. Li et al., "Characteristics and sources of polycyclic aromatic hydrocarbons in atmospheric aerosols in the Kathmandu Valley, Nepal," Science of the Total Environment, vol. 538, pp. 86-92, 2015.

[30] A. Katsoyiannis and K. Breivik, "Model-based evaluation of the use of polycyclic aromatic hydrocarbons molecular diagnostic ratios as a source identification tool," Environmental Pollution, vol. 184, pp. 488-494, 2014

[31] X. L. Zhang, S. Tao, W. X. Liu, Y. Yang, Q. Zuo, and S. Z. Liu, "Source diagnostics of polycyclic aromatic hydrocarbons based on species ratios: a multimedia approach," Environmental Science \& Technology, vol. 39, no. 23, pp. 9109-9114, 2005.

[32] N. R. Khalili, P. A. Scheff, and T. M. Holsen, "PAH source fingerprints for coke ovens, diesel and, gasoline engines, highway tunnels, and wood combustion emissions," Atmospheric Environment, vol. 29, no. 4, pp. 533-542, 1995.

[33] Y. Wu, L. Yang, X. Zheng et al., "Characterization and source apportionment of particulate PAHs in the roadside environment in Beijing," Science of the Total Environment, vol. 470-471, pp. 76-83, 2014.

[34] J. Dong, J. Wang, G. Zhang et al., "Population exposure to PAHs and the health risk assessment in Lanzhou city," Ecology \& Environmental Sciences, vol. 21, no. 2, pp. 327-332, 2012 (Chinese).

[35] R. Martí-Cid, J. M. Llobet, V. Castell, and J. L. Domingo, "Evolution of the dietary exposure to polycyclic aromatic hydrocarbons in Catalonia, Spain," Food and Chemical Toxicology, vol. 46, no. 9, pp. 3163-3171, 2008. 

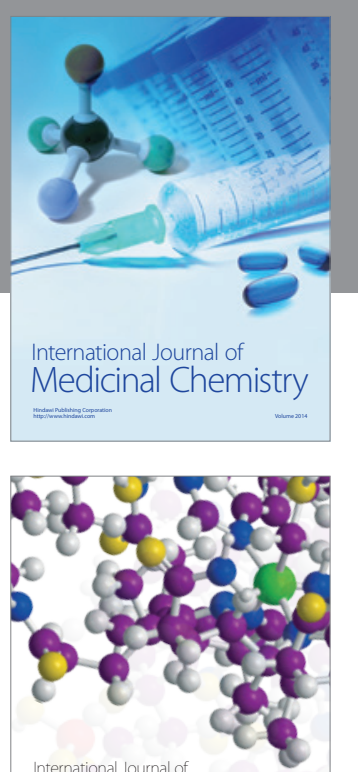

Carbohydrate Chemistry

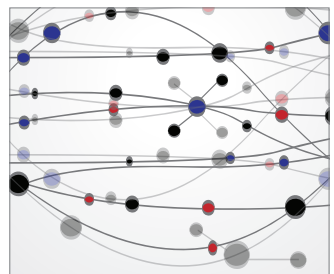

The Scientific World Journal
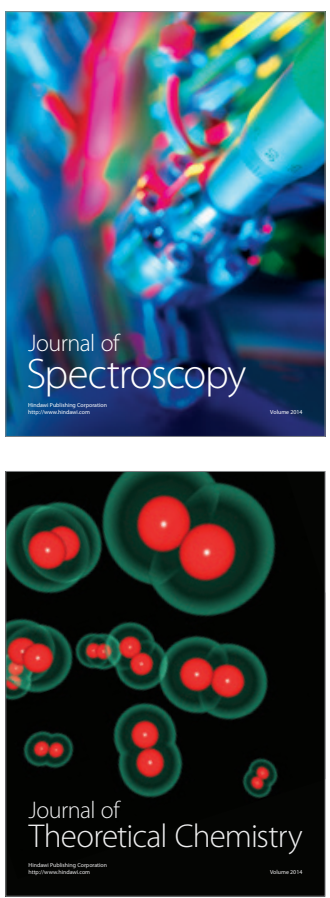
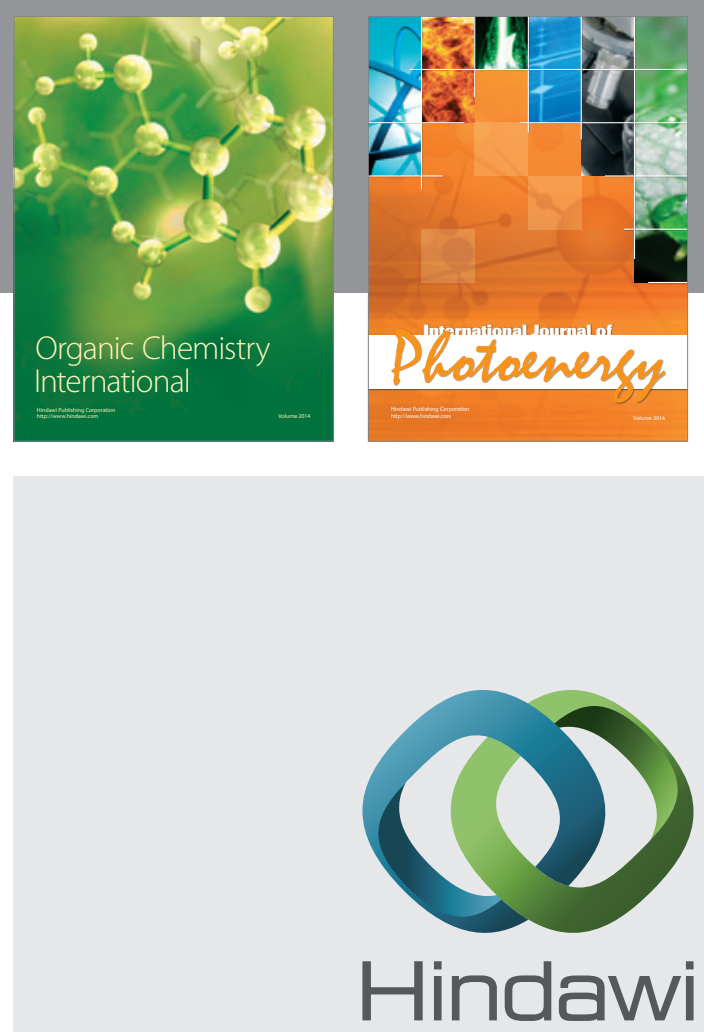

Submit your manuscripts at

http://www.hindawi.com

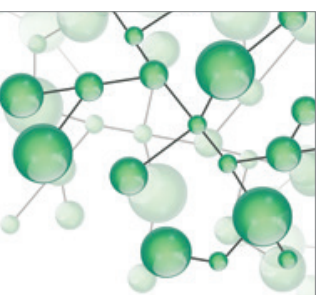

International Journal of

Inorganic Chemistry

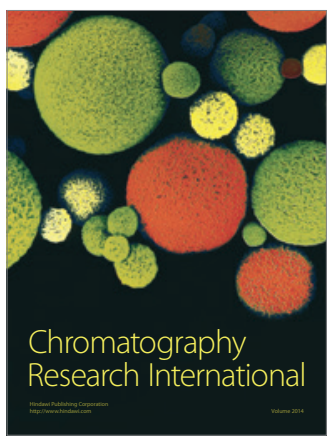

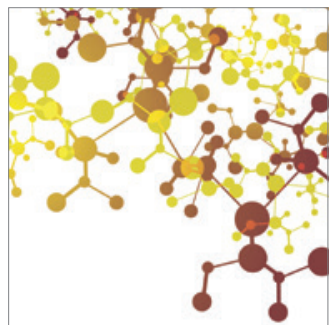

Applied Chemistry
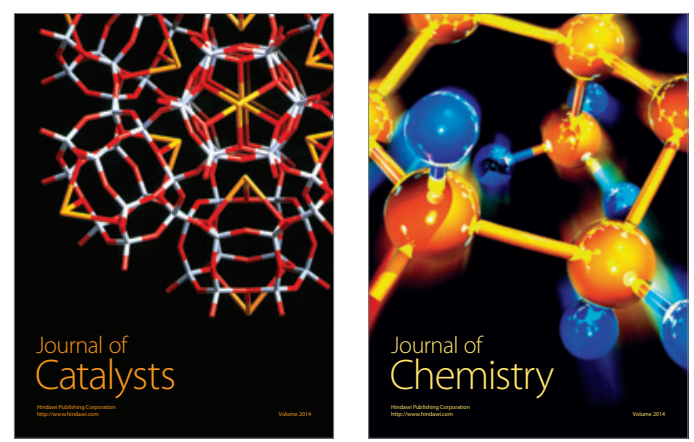
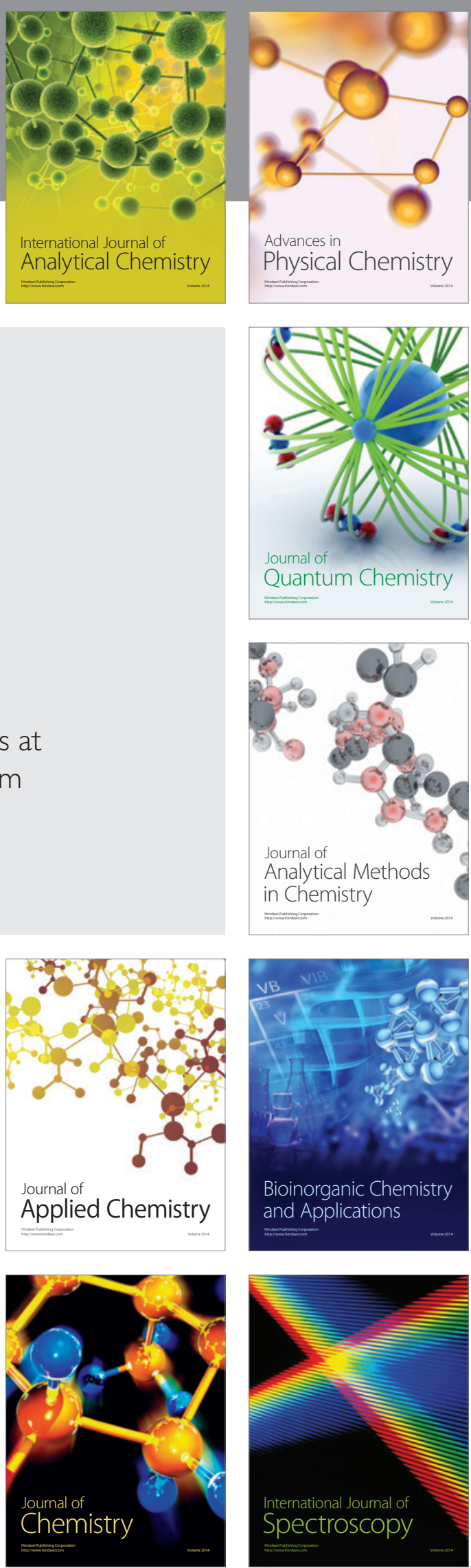